\title{
O empoderamento feminino e as políticas públicas para o espaço rural: o caso do Projeto Semeadura
}

\author{
Women's empowerment and public policies for rural areas: the case of the Semeadura Project
}

Ivanio Folmer

Doutorando do Programa de Pós-Graduação em Geografia Universidade Federal de Santa Maria - UFSM, RS, Brasil ivaniofolmer@yahoo.com.br

Gabriella Eldereti Machado Doutoranda do Programa de Pós-Graduação em Educação Universidade Federal de Santa Maria - UFSM, RS, Brasil gabriellaeldereti@gmail.com

Isabela Mello

Doutoranda do Programa de Pós-Graduação em Geografia Universidade Federal de Santa Maria - UFSM, RS, Brasil isaasmello@hotmail.com

Ana Margarida Piani Ferreira Mestranda do Programa de Pós-Graduação em Geografia Universidade Federal de Santa Maria - UFSM, RS, Brasil margaridapiani@yahoo.com.br

\section{Resumo}

As políticas públicas voltadas às mulheres rurais garantem os direitos e o acesso à documentação, à terra, ao crédito, à produção agroecológica, aos serviços de assistência técnica e extensão rural, à comercialização e agregação de valor à produção, à participação na gestão, ao desenvolvimento territorial e à manutenção da memória coletiva e dos conhecimentos tradicionais. Objetiva-se no presente trabalho discutir sobre alguns movimentos de mulheres do meio rural, trazendo, neste artigo, as atividades do Projeto Semeadura, que é resultado da parceria entre Ministério do Desenvolvimento Agrário e a organização da Sociedade Civil de Interesse Público a Guayí. Este tem como objetivo para sua realização, contribuir para o fortalecimento da auto-organização das mulheres trabalhadoras rurais, por meio de sua participação nos espaços de gestão social, na perspectiva de um desenvolvimento rural sustentável e solidário, contribuindo para a redução das desigualdades de gênero e para a ampliação do protagonismo das mulheres do campo.

Palavras-Chave: Trabalhadoras Rurais; Empoderamento das Mulheres; Feminismo; Políticas Públicas para Mulheres Rurais.

\begin{abstract}
Public policies aimed at rural women guarantee the rights and access to documentation, land, credit, agroecological production, the technical assistance and rural extension services, marketing and adding value to production, participation in management, territorial development and maintenance of collective memory and traditional knowledge. The objective in the present work discusses some women's movements in rural areas, bringing the activities of the Sowing Project, which is a partnership between the Ministry of Agrarian Development and the organization of the Civil Society of Public Interest to Guayi. Aims for its realization contribute to strengthening the selforganization of rural women workers, through their participation in the spaces of social
\end{abstract}


management with a view to sustainable and solidary rural development, contributing to the reduction of gender inequalities and the expanding the role of women.

Keywords: Rural Workers; Women's empowerment; Feminism; Public policies for rural women.

\section{INTRODUÇÃO}

Os movimentos sociais tem representado grande avanço na conquista de políticas públicas, consolidando-se na luta pela terra, na concretização dos assentamentos rurais, aliando-se à organização sindical no enfrentamento aos embates referentes à previdência social, e o crédito destinado aos sujeitos do campo.

Por essa razão, consegue-se perceber que os movimentos sociais do campo, utilizando sua força de mobilização, auxiliam na redução da margem das desigualdades entre os territórios; Urbano e Rural, ampliando olhares quanto à participação das mulheres, na reivindicação de seus direitos e políticas pertinentes ao campo.

Ao refletir-se sobre a abertura democrática no Brasil, dialoga-se acerca do levante de lutas através da mobilização social de vários movimentos e organizações populares. Neste contexto há o destaque à inserção das trabalhadoras rurais para conquistar o reconhecimento de seu trabalho no campo e, na garantia dos seus direitos, alcançar melhores condições de vida.

Desse modo, com um ambiente que abriu espaço às mobilizações sociais, deu-se início e origem os movimentos das mulheres do/no campo conhecidos no âmbito nacional e internacional, como: a Marcha das Margaridas e o Movimento de Mulheres Camponesas e das mulheres do Movimento dos Trabalhadores Sem Terra (MST). Esses movimentos possuem como peça-chavecomum o protagonismo feminino, o qual contribui para o fortalecimento das ações coletivas das mulheres.

Somente na década de 2000, com uma nova conjuntura política do País, começam a acontecer algumas mudanças em relação ao diálogo entre governo e os movimentos sociais, tendo estes uma maior participação em decisões como a destinação de recursos, estruturação das ações e redefinições institucionais. Através dessa aproximação, permitiu-se a ocorrência de ações integradas entre o Programa de Promoção da Igualdade de Gênero, Raça e Etnia do Ministério de Desenvolvimento Agrário em conjunto com a Secretaria de Políticas para as Mulheres, possibilitando resultados como mudanças em relação à remuneração das mulheres, assim como a criação da política de crédito específico através do Pronaf ${ }^{1}$ Mulher, e o Programa Nacional de documentação da Trabalhadora Rural.

\footnotetext{
${ }^{1}$ Programa Nacional de Fortalecimento da Agricultura Familiar.
} 
Objetiva-se neste texto discutir sobre alguns, dos muito, movimentos de mulheres do espaço rural, trazendo as atividades do Projeto Semeadura como referência. Busca-se através do Projeto Semeadura problematizar a articulação, fortalecimento e empoderamento das mulheres e sua auto-organização voltada ao desenvolvimento rural solidário, sustentável e feminista.

\section{OS MOVIMENTOS DE MULHERES DO CAMPO: A MARCHA DAS MARGARIDAS E O MOVIMENTO DAS MULHERES CAMPONESAS}

A participação política e intervenções do movimento de mulheres rurais em demasiados espaços e territórios, contribuíram de forma significativa para reconhecimento e conquista de direitos (SILIPRANDI; CINTRÃO, 2015). Um desses movimentos, envolvendo a participação das mulheres rurais ficou conhecido como a Marcha das Margaridas, o qual é/foi um movimento de ação estratégica de mulheres do campo, da floresta e das águas que começou a ser realizado no ano de 2000, com um enfoque formativo de diálogo e negociação política com o governo, propondo-se a impulsionar a construção de políticas públicas, sendo coordenado, principalmente pela CONTAG ${ }^{2}$ e sindicatos dos (as) trabalhadores (as), dentre outras instituições.

As mulheres que compõem o Movimento das Margaridas debatem acerca de temas cotidianos envolvendo o feminismo no Espaço Rural, acompanhando de perto as discussões políticas, sociais, culturais e econômicas, evidenciando o papel e a situação das mulheres em meio a toda a configuração do campo hoje (CONTAG, 2015). Um dos principais desafios do movimento é dar visibilidade aos territórios rurais e aos sujeitos envolvidos, resultando em uma participação do povo que contribui na formulação e aplicação das políticas públicas como educação, saneamento, habitação, apoio a produção.

O Movimento das Mulheres Camponesas (MMC) articula-se através de iniciativas que priorizam o fim do preconceito e violências contra a mulher, contribuindo para que tenham maior autonomia e emancipação. O movimento das Mulheres Camponesas surgiu na década de 1980 (MMC BRASIL, 2020³), assim como outros movimentos sociais motivados pela abertura democrática que o País estava vivendo, trazendo em sua "bandeira" de luta a valorização das trabalhadoras rurais, com os seguintes objetivos traçados pelo movimento: a libertação da mulher, sindicalização, documentação, direitos previdenciários como salário maternidade e aposentadoria, participação política, dentre outros.

A cartilha do Feminismo Camponês e Popular (2018, p.10) traz: “[...] a missão de libertação das mulheres trabalhadoras de qualquer tipo de opressão e discriminação. Isso se

\footnotetext{
${ }^{2}$ Confederação Nacional de Trabalhadores na Agricultura.

${ }^{3}$ Informação disponível em: http://www.mmcbrasil.com.br/site/node/44, acesso em: 04.07.2020.
} 
concretiza nas lutas, na organização, na formação e na implantação de experiências de resistência popular, onde as mulheres sejam protagonistas de sua história”.

Para o MMC $(2020)^{4}$, a definição de mulher camponesa é: “[...] aquela que produz o alimento e garante a sobrevivência da família, ou seja, é a pequena agricultora, a pescadora artesanal, a quebradeira de coco, as extrativistas, ribeirinhas, boias-frias, sem terra, acampadas e assentadas, assalariadas rurais e indígenas".

O MMC legitima, entre diversos contextos, uma luta central contra o modelo capitalista e patriarcal, defendendo um Projeto Popular de Agricultura Camponesa, onde se destacam as seguintes demandas: viabilização de políticas públicas para a agricultura que garantam a permanência das jovens mulheres no campo, a produção de alimentos saudáveis, crédito especial para mulheres; a defesa, preservação, multiplicação e conservação da biodiversidade, patrimônio da humanidade a serviço dos povos, garantindo com isso, a soberania alimentar.

Desse modo, os inúmeros movimentos de mulheres nos territórios rurais, são sem dúvida, uma contraposição ao modelo hegemônico da agricultura capitalista, pois pensa, a partir da sua realidade, um projeto de sociedade, sem desigualdades, de valorização à vida, aos elementos naturais, à fauna e à flora, com acesso e permanência à terra e à educação.

Por tratar-se de um movimento social, necessita ser pensado e, consolidado por Políticas Públicas que venham atender às necessidades e interesses dessas mulheres, cumprindo com o papel de ampará-las, sobretudo porque vivem e lutam pelos seus territórios, por elas, pelas filhas, amigas, vizinhas...

\section{POLÍTICAS PÚBLICAS PARA MULHERES RURAIS NO BRASIL: UM DEBATE PRELIMINAR}

De acordo com Maria Luiza Amaral Rizzoti (2001), a partir do surgimento, as políticas públicas do Brasil possuem estrutura desenvolvimentista subordinada aos países capitalistas centrais reguladores hegemônicos, o que de certo modo estaria seguindo a lógica dominante capitalista, hegemônica e patriarcal anunciada por Gayatri Chakravorty Spivak (2014) servindo, especialmente, aos interesses econômicos internacionais. Contudo, as políticas sociais devem conduzir estratégias para garantir melhorias nas condições de vida das cidadãs e dos cidadãos. Por isso, Eloisa de Matos Hofling (2001) vê as políticas públicas como ações do Estado voltadas para a redistribuição dos benefícios sociais, as quais visam à redução das desigualdades estruturais produzidas pelo fomento ao desenvolvimento econômico.

As políticas públicas direcionadas especialmente para as mulheres brasileiras buscaram fornecer benefícios sociais a determinados grupos de mulheres ao longo da efetivação do país.

\footnotetext{
${ }^{4}$ Informação disponível em: http://www.mmcbrasil.com.br/site/node/44, acesso em: 04.07.2020.
} 
Desse modo, é notória a ausência de políticas voltadas para muitas que ainda não foram contempladas por essas ações. Muitas vezes estas, não se enquadram nos critérios estabelecidos pelas políticas.

As políticas públicas voltadas às mulheres rurais garantem o acesso aos direitos, dentre eles à documentação pessoal, à terra, ao crédito, à produção agroecológica, aos serviços de assistência técnica e extensão rural, à comercialização e agregação de valor à produção, à participação na gestão, ao desenvolvimento territorial e à manutenção da memória coletiva e dos conhecimentos tradicionais. Estas políticas, são asseguradas pela criação do Plano Nacional de Desenvolvimento Rural Sustentável e Solidário (MDA, 2013), buscando uma igualdade entre gêneros. “[...] As mulheres são responsáveis, em sua maioria pela produção que se destina ao autoconsumo familiar, e também vem conquistando espaço nas práticas agroecológicas e de reprodução de sementes crioulas" (BRASIL, 2013).

Vale ressaltar que as políticas públicas voltadas às mulheres que exercem atividades agrícolas no país são recentes. Desse modo, Hofling (2001) acredita que “[...] é papel fundamental das políticas públicas estabelecerem programas de ação que universalizem, que favoreçam a incorporação de conquistas sociais pelos grupos mais desfavorecidos, atentos a mudanças instituídas que culminaram ao desequilíbrio social". Visualiza-se, que é função das políticas governamentais atender as distintas demandas das inúmeras mulheres, e suas realidades que compõem os demasiados territórios do Brasil.

Algumas demandas das mulheres atendidas por políticas públicas tiveram sua gestão inicial nos debates dos grupos de mulheres trabalhadoras rurais, presentes em diversas partes do país. Losandro Antônio Tedeschi (2007) identifica esses grupos “[...] com raízes ligadas a pequenos grupos de mulheres com vinculo à igreja (especialmente a católica), as quais posterior aos encontros dominicais, pós-missas, reuniam-se para debater acerca das condições das mulheres no espaço rural".

Esse movimento inicial culminou com o surgimento do Programa Nacional de Documentação da Trabalhadora Rural e teve como objetivo "assegurar às mulheres rurais o acesso e aquisição da documentação civil básica, previdenciária e trabalhista" (BRASIL, 2009). Esse programa, é realizado através de mutirões itinerantes,-percorrem as localidades do território nacional emitindo os documentos. O processo de gestão e participação territorial é um meio de promover o fortalecimento dos Comitês Territoriais de Mulheres, buscando acesso a políticas públicas e atividades de formação, mobilização e articulação.

A Política de Desenvolvimento Territorial através do Projeto de Infraestrutura e Serviços em Territórios Rurais (PROINF) conta com projetos de infraestrutura, garantindo às mulheres inscritas no programa, cerca de $40 \%$ dos recursos destinados pelos editais (PROINF, 2012). 
Também é garantida a participação no Conselho Nacional de Desenvolvimento Rural propondo a discussão das estratégias de desenvolvimento rural com igualdade de gênero. O PROINF (2012) prevê ainda investimentos de fortalecimento da agricultura familiar, da gestão social e das redes de cooperação, como também a formação de agentes de desenvolvimento locais para articulação e integração das políticas públicas nos Territórios da Cidadania.

No que tange à reforma agrária, há uma problemática já inserida por Fischer e Gehlen (2002) na qual afirmam:

Do ponto de vista patriarcal a terra é um patrimônio e, como tal, deve pertencer ao homem. A mulher, como dependente do pai ou do marido, de acordo com o direito consuetudinário ou positivo, somente tem a possibilidade de administrar e se desfazer da terra em caso de morte do referencial masculino e, mesmo assim teoricamente, pois, a perda desse referencial, o patrimônio deve ser mantido como bem masculino. (FISCHER; GEHLEN, 2002, p. 22).

A partir dos dados apresentados pelo primeiro Censo da Reforma Agrária (1996) fica visível a participação de mulheres assentadas, contudo é ressaltado que essa participação não se efetiva pela pressão ou sugestão do Estado. Neste documento e em outras pesquisas a realidade é bastante semelhante: Para que seja efetivado o direito conquistado na lei não foram garantidos pelo esforço do Estado; os procedimentos administrativos para inscrição, seleção e destinação dos lotes da reforma agrária continuam os mesmos.

A política interna do movimento dá as mulheres condições de conquistar a terra de forma igualitária. Desse modo, durante o II Plano Nacional de Reforma Agrária (PNRA) foi assumido o compromisso de enfrentar o "[...] padrão secular de subordinação e negação das mulheres rurais enquanto sujeitos políticos e econômicos do mundo rural, assumindo que cabe ao Estado a implementação de políticas dirigidas à superação dessa situação de desigualdade social” (MDA, 2004, p.23).

O Programa Nacional de Crédito Fundiário (PNCF), de acordo com o MDA (2015), permite a incorporação de áreas que não podem ser desapropriadas e é executado de forma descentralizada, nos estados, tendo como órgão executor as Unidades Técnicas Estaduais (UTEs), estabelecendo que as mulheres também possam ter título dos imóveis rurais. Fica garantida a escrituração conjunta quando os mutuários e as mutuárias constituírem um casal em situação de casamento ou união estável. O Programa Nacional de Fortalecimento da Agricultura Familiar Pronaf Mulher ${ }^{5}$ corresponde a uma linha de Pronaf específica que estimula o trabalho das mulheres rurais na agricultura familiar e nos assentamentos da reforma agrária, sendo a oportunidade para desenvolver atividades agrícolas e não agrícolas, facilitando o acesso à linha de crédito destinada à Unidade de Produção Familiar.

\footnotetext{
${ }^{5}$ Informação disponível em: http://www.ceplac.gov.br/radar/Artigos/artigo26.htm, acesso em: 04.07.2020.
} 
Tendo em visto o percurso teórico discutido até o momento, esse texto articula-se em observação, contribuição e análise do Projeto Semeadura, o qual a partir de desdobramentos acontece em virtude de ações coletivas femininas, em vistas à emancipação das mulheres no contexto das realidades rurais.

\subsection{Projeto Semeadura: Caminhos percorridos}

O Projeto Semeadura é resultado da parceria entre Ministério do Desenvolvimento Agrário e a Organização da Sociedade Civil de Interesse Público, a Guayí. Tem como objetivo para sua realização contribuir para o fortalecimento da auto-organização das mulheres trabalhadoras rurais, por meio de sua participação nos espaços de gestão social, na perspectiva de um desenvolvimento rural sustentável e solidário, contribuindo para a redução das desigualdades de gênero e para a ampliação do protagonismo das mulheres. Atribui-se às mulheres, a grande responsabilidade pela diversidade existente na agricultura tradicional, a observar sua trajetória ligada à questão da preservação das sementes crioulas e ao cuidado com a terra. Do mesmo modo, são grandes representantes da natureza, por seus grupos coletivos discutirem possibilidades sustentáveis da relação com ambiente.

O Projeto Semeadura abrange 6 Territórios da Cidadania $^{6}$, sendo 4 no estado do Rio Grande do Sul e 2 no estado do Paraná. No Rio Grande do Sul temos: Região Sul, Região Central, Região Noroeste Colonial e Região Médio Alto Uruguai, estes, estão ilustrados na figura 1.

No estado do Paraná temos os territórios de Cantuquiriguaçu e Paraná Centro, ilustrados na figura 2.

Desse modo, o projeto Semeadura não se limita a uma cidade, ou Estado, construindo condições de desenvolver em outros territórios, já que geográfica e socialmente o Brasil possui formação territorial semelhante. A fim de prestar esclarecimentos acerca da forma com a qual acontece o projeto, elenca-se abaixo (Tabelas 1 e 2) o processo desde a organização, transitando até a execução.

\footnotetext{
${ }^{6}$ O Programa Territórios da Cidadania foi criado em 2008 e articula diferentes áreas do executivo visando à integração de políticas. Adota uma estratégia de gestão descentralizada e articulam ações entre os diferentes entes federados União, Estados e Municípios - com ampla participação social na definição de prioridades, planejamento e controle social para o desenvolvimento econômico e social.
} 


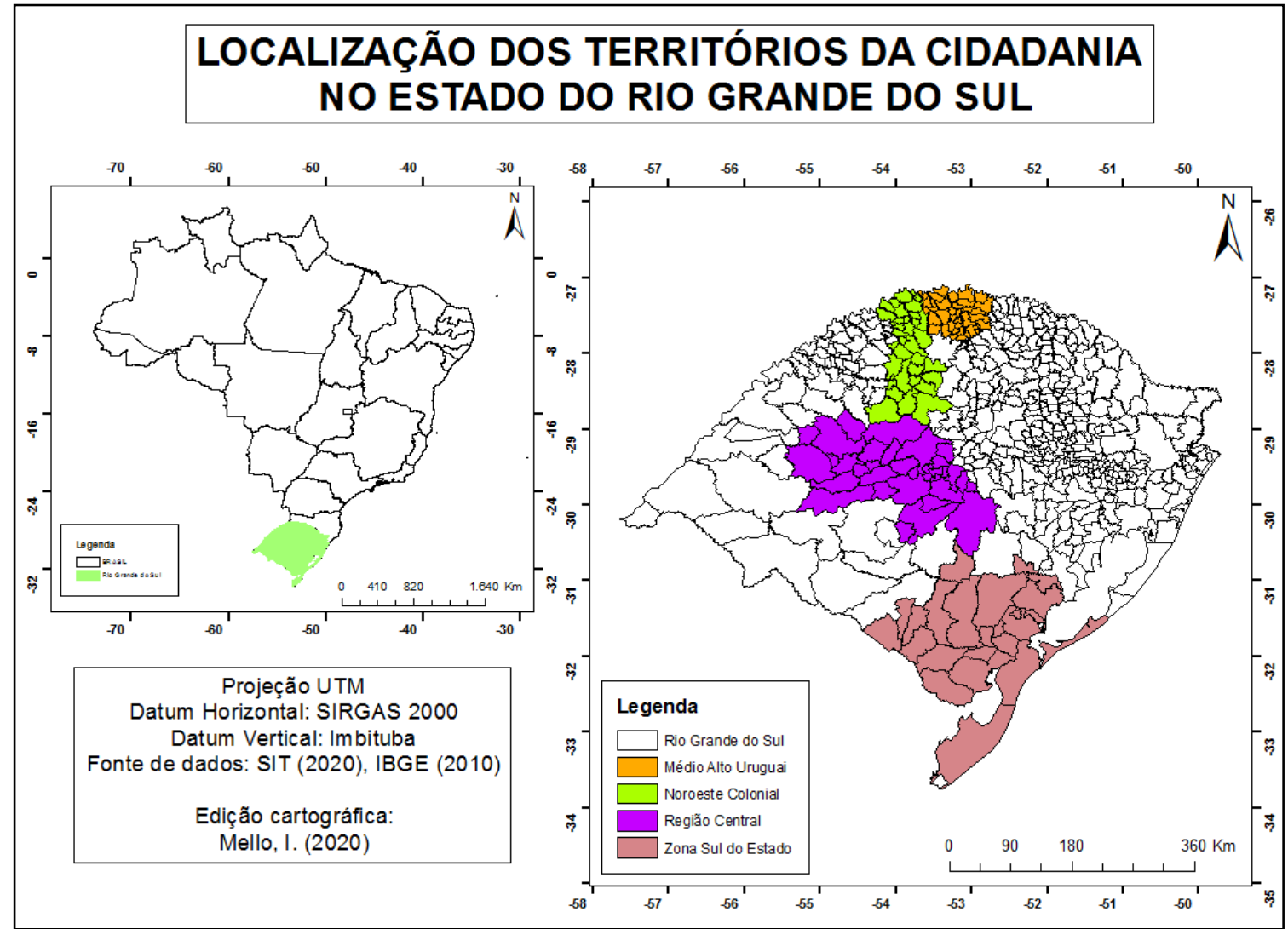

Figura 1 - Mapa de localização dos Territórios da Cidadania no Rio Grande do Sul.

Fonte: Autores, 2020.

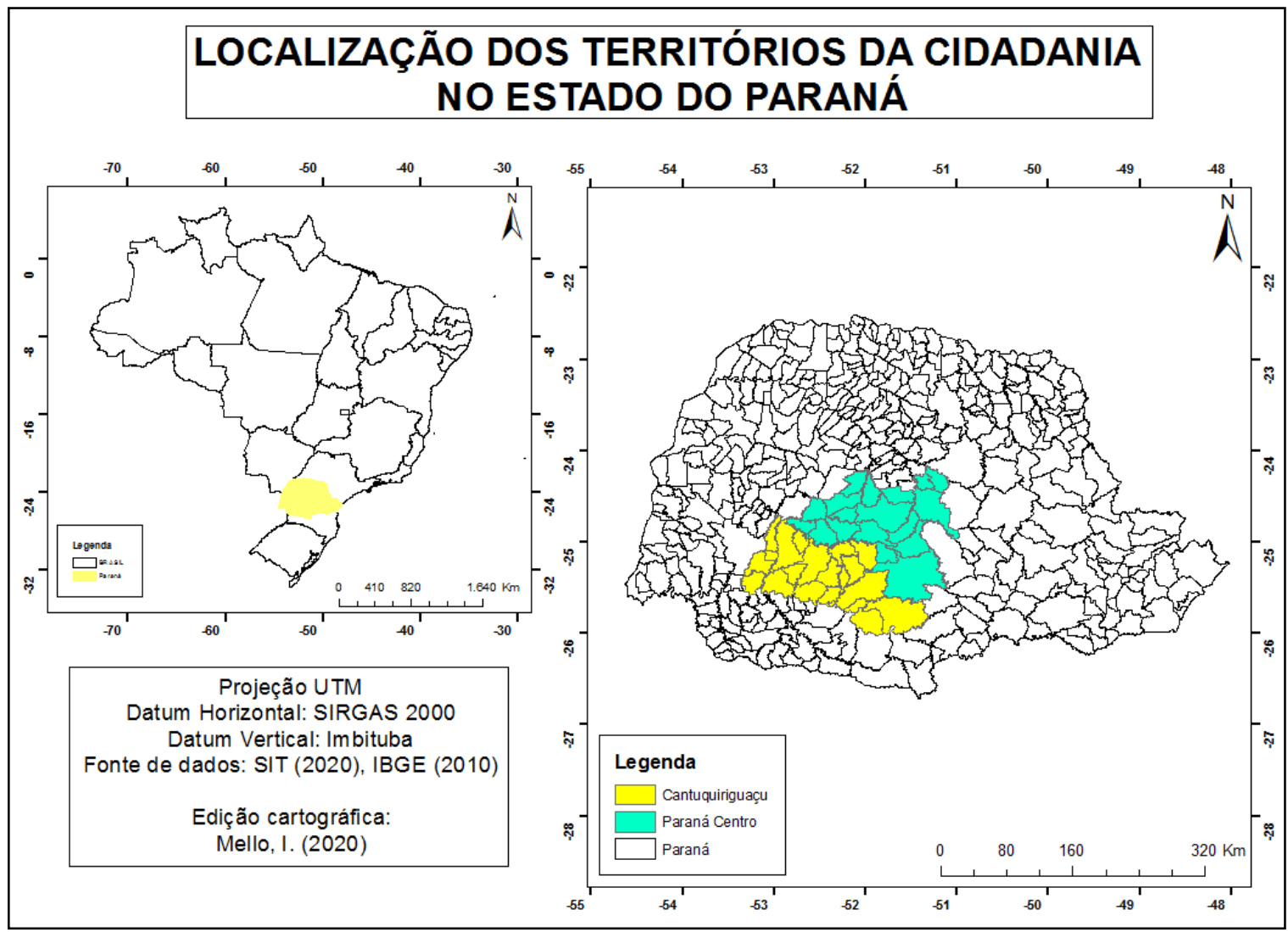

Figura 2 - Mapa de localização dos Territórios da Cidadania no Paraná.

Fonte: Autores, 2020 
Tabela 1 - Meta 1: Fortalecimento da participação das mulheres nos espaços dos colegiados territoriais.

\begin{tabular}{|c|c|}
\hline AÇÃO & DESCRIÇÃO DA AÇÃO \\
\hline Ação 1.1 & $\begin{array}{l}\text { Encontro de articulação e rearticulação com o comitê territorial } \\
\text { de mulheres rurais dos Territórios da Cidadania. }\end{array}$ \\
\hline Ação 1.2 & $\begin{array}{c}\text { Oficina de socialização dos resultados das Conferências } \\
\text { Territoriais, Estaduais e Nacionais de Desenvolvimento Rural } \\
\text { Sustentável. }\end{array}$ \\
\hline Ação 1.3 & $\begin{array}{c}\text { Encontro estadual com os Comitês Territoriais de Mulheres } \\
\text { Rurais. }\end{array}$ \\
\hline
\end{tabular}

Fonte: Autores, 2020.

Tabela 2 - Meta 02: Capacitação para o acesso das mulheres às políticas públicas de inclusão produtivas.

\begin{tabular}{|c|c|}
\hline AÇ्̃̃O & DESCRIÇÃO DA AÇÃO \\
\hline Ação 2.1 & $\begin{array}{l}\text { Oficina Estadual de capacitação em política pública e } \\
\text { desenvolvimento rural sustentável tendo como referência os } \\
\text { princípios à economia feminista e solidária, agroecologia e à } \\
\text { socialização do trabalho doméstico e do cuidado. }\end{array}$ \\
\hline Ação 2.2 & Cartilha. \\
\hline Ação 2.3 & $\begin{array}{l}\text { Oficina Estadual de articulação para efetivação e ampliação da } \\
\text { rede de educação infantil nos Territórios. }\end{array}$ \\
\hline
\end{tabular}

Fonte: Autores, 2020.

As atividades dentro das ações, acontecem através de um processo lento de conhecimento das mulheres e dos territórios onde estão inseridas, considerando que são necessários momentos de problematização e reflexão acerca do vivido e sentido.

\section{METODOLOGIA}

No que se refere à metodologia de pesquisa, utilizou-se inicialmente rebuscada e intensa pesquisa bibliográfica em relação aos processos que se vinculam e resultam nas ações atuais do Projeto, nesta etapa foram utilizadas diversas fontes para estabelecer as relações que permeiam o tema abordado, visto que não é algo isolado, podendo-se conhecer as contribuições sobre a temática realizadas por outros autores, (KÖCHE, 1997).

De forma prática, adotou-se a Metodologia de Grupos Reflexivos de Gênero (2016), método que proporciona a realização de dinâmicas de grupos, com o objetivo de reflexão e problematização sobre as questões que permeiam o grupo analisado, no caso deste trabalho, as mulheres do espaço rural que participam do Projeto Semeadura. Não há como desconsiderar que se fez um estudo de caso, todavia, essa pesquisa está inserida nesse procedimento, uma vez que compreendemos que,

Em geral, os estudos de caso representam a estratégia preferida quando se colocam questões do tipo 'como' e 'por que', quando o pesquisador tem pouco controle sobre os acontecimentos e quando o foco se encontra em fenômenos contemporâneos inseridos em algum contexto da vida real (YIN, 2005, p. 19). 
Desse modo, há uma abordagem qualitativa, a qual mantem como foco a Metodologia de Grupos Reflexivos de Gênero; a mesma foi desenvolvida por Beiras e Bronz (2016), exercitando sua aplicação com grupos de: homens e mulheres que haviam vivido situações de violência de gênero e, com homens, mulheres e transgêneros, nas comunidades, escolas, hospitais, e muitos outros espaços sociais.

Desse modo, procurou-se embasamento na proposta metodológica descrita anteriormente, propondo atividades práticas com o Projeto Semeadura, o qual realizou-se em três encontros em grupo, com as mulheres participantes.

Abaixo a descrição das ações realizadas:

No primeiro encontro ocorreu a apresentação do projeto às participantes, e a organização de uma atividade em grupo, tendo as seguintes perguntas norteadoras:

1. Conhece a política territorial?

2. O que espera com a realização do projeto no seu território?

3. Quais as propostas para o comitê de mulheres do território?

As atividades do projeto foram realizadas no Centro de Referência em Economia Solidária Dom Ivo Lorscheiter na cidade de Santa Maria no Estado do Rio Grande do Sul. Esse momento de aproximação inicial foi de extrema importância para projetar discussões e problematizações contextualizadas em grupo, ampliando novas discussões posteriores, conforme exemplifica a figura 3.

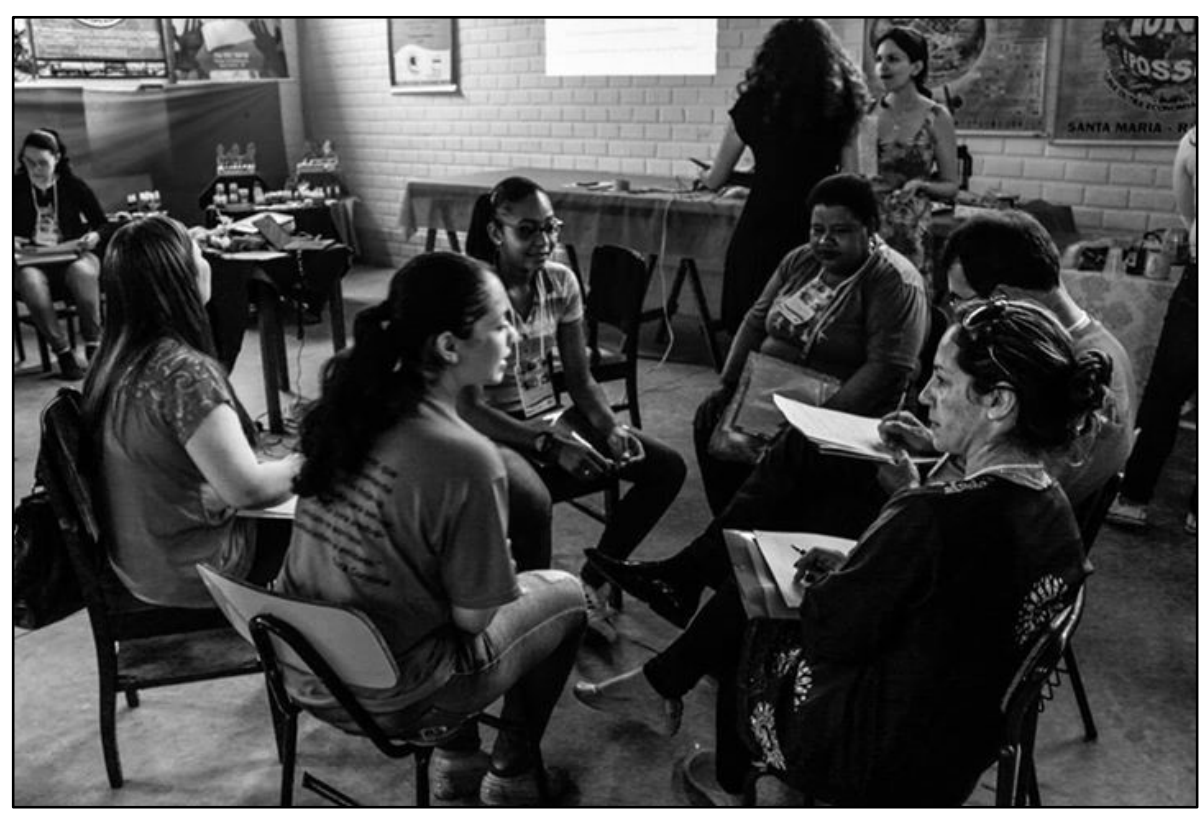

Figura 3 - Atividade realizada no Projeto Semeadura.

Fonte: Projeto Semeadura, 2015. 
No segundo encontro, realizou-se a oficina de socialização dos resultados da Conferência Nacional de Desenvolvimento Rural sustentável e solidário, o qual, segundo a CONTAG (2015), foi iniciado em abril de 2013 e trouxe em seu bojo discussões acerca das condições territoriais, intermunicipais, municipais, setoriais; temáticas livres, estaduais, distrital e nacional. A CONTAG acompanhou o evento de perto e convocou a todas as lideranças de base, dirigentes dos Sindicatos dos Trabalhadores e Trabalhadoras Rurais (STTRs), das Federações de Trabalhadores na Agricultura (FETAGs) e os trabalhadores e trabalhadoras rurais a participar dos eventos que estavam sendo realizados.

Nesse encontro foi possível dialogar acerca das realidades territoriais em que cada participante estava inserida, bem como promover uma interlocução de saberes tradicionais, haja vista da importância da comunicação entre os territórios. Desse modo, oportunizou-se um momento de trocas de mudas, de ervas medicinais (chás) da Aldeia da Paz, considerando a importância destes para a vida no campo.

Posteriormente foi retomado o trabalho em grupos, através da pergunta norteadora: Como podemos executar as políticas em nosso território?

A problematização faz com que seja desencadeado um leque de possibilidades, as quais, inicialmente, elaboradas de forma individual e posteriormente acompanhadas e construídas de forma coletiva.

Dentre os principais desejos das mulheres destacaram-se: O desejo de que sejam cumpridas as leis contra os agressores físicos, os quais muitas vezes são os companheiros ou ex companheiros; Implementação de ações que diminuam os estereótipos de gênero e, proteção às mulheres no que diz respeito a exploração sexual. Segundo às participantes do projeto, somente a partir disso é que se pode alcançar o mínimo das políticas públicas. Outro ponto abordado diz respeito à informação pessoal, as mesmas, discorrem que ainda há desconhecimento e medo por parte de muitas mulheres em seus territórios, haja vista que são vítimas cotidianas e não reconhecem que estão passando por agressões ou violências.

Desse modo destaca-se a importância de uma hiper-vigilância em torno das mulheres em todos os territórios, em especial as que vivem afastadas dos espaços urbanos, a-considerando que, muitas vezes não há comunicação com pessoas estranhas ao meio familiar, onde geralmente ocorrem as agressões.

Na terceira etapa, ocorreu o evento intitulado "I Feira de Trocas de Sementes e Mudas Crioulas das Mulheres Rurais do Território Central”, que foi uma forma de fortalecer os laços entre as participantes após a discussão de suas experiências e contextos.

Neste momento, as protagonistas tiveram a oportunidade de socializar as práticas desenvolvidas em seus territórios a fim de compartilhar modos e jeitos específicos de forma 
coletiva. Desse modo a Feira de Troca de Sementes foi mais do que trocar sementes, foi retomar questões muitas vezes esquecidas, de como plantar, cuidar e perpetuar suas ancestralidades, configuradas nas mudas e sementes.

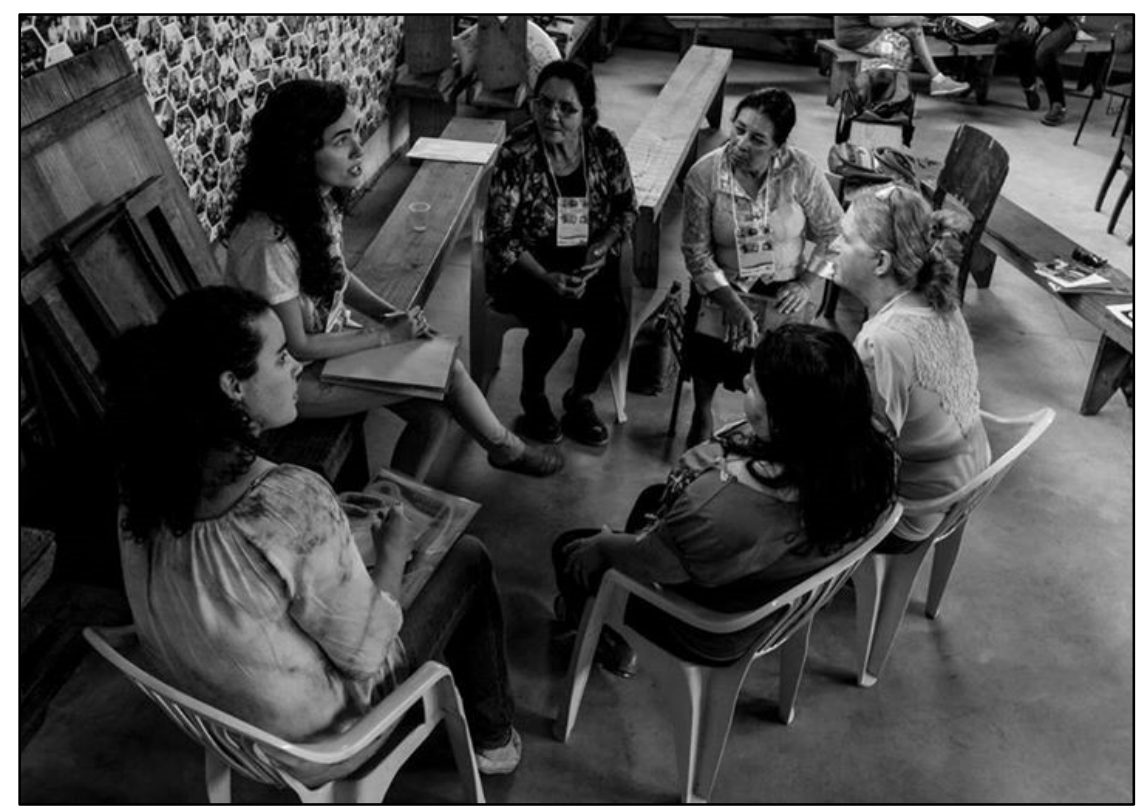

Figura 4 - Atividade: Como podemos executar as políticas em nosso território? Fonte: Projeto Semeadura, 2015.

O primeiro passo do evento foi destinado de fato às trocas de sementes e mudas. Destaque em especial para sementes de: milho, feijão, abóbora e melancia. Fez-se especialmente presente, mudas de plantas frutíferas, as quais muitas vezes são cultivadas em suas propriedades, seguidas de mudas de flores.

Na sequência, as mulheres participantes foram convidadas a contribuir com um prato feito exclusivamente a partir de produtos cultivados em suas propriedades, em especial, foi pedido que para essa confraternização, de encerramento dessa etapa, fossem preparadas receitas historicamente repassadas de geração em geração; também era oferecida a receita destacando os produtos e a forma de preparo, como forma de resgatar e preservar a história das mulheres e da culinária ancestral, deixada de lado, à medida que os mercados se aproximam das comunidades.

Ao oportunizar esses espaços, compreendemos o mesmo enquanto esforço de explorar a sustentabilidade, além da validação das histórias de cada uma das mulheres, na criação de vínculos e trocas de experiências, o que culminou a uma interligação política e social entre as mulheres, fortalecendo os vínculos em direção à emancipação e empoderamento feminino. 


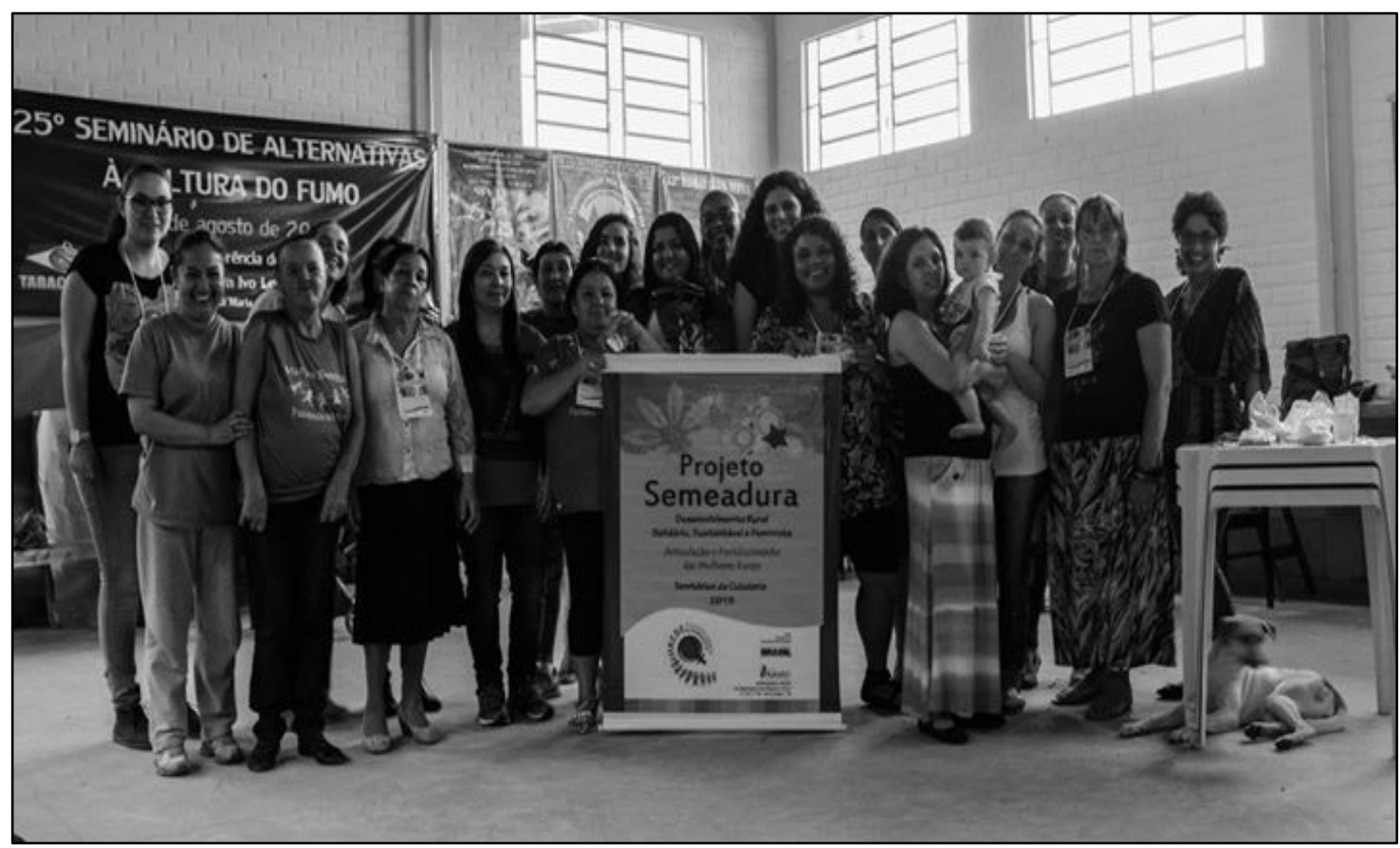

Figura 5 - I Feira de Trocas de Sementes e Mudas Crioulas das Mulheres Rurais do Território Central. Fonte: Projeto Semeadura, 2015.

Ainda na terceira etapa, ao serem entrevistadas, três participantes, denominadas aqui como flores: Rosa, Girassol e Camélia, responderam à seguinte pergunta: Qual sua avaliação sobre o Projeto Semeadura e sua perspectiva de melhoria das condições de vida no seu território?

Rosa: "Interessante, importante para aumentar a organização das mulheres. Esperamos conhecer melhor as politicas para mulheres e nos organizarmos para elas".

Girassol: "O projeto é de suma importância, pois é um meio de proporcionar a interação entre mulheres de várias localidades, fazendo assim a acolhida daquelas que não tem suporte algum. Almejo uma luta mais igualitária entre homens e mulheres rurais, pois os ideais e objetivos devem ser os mesmos".

Camélia: "Positiva". Ajuda as mulheres a ter mais espaço na agricultura e ter mais atitudes junto às decisões tomadas em grupo. Seria interessante falar mais sobre agricultura familiar".

A proposta dessas provocações objetivou promover um espaço de reflexão. Em uma breve análise a partir da finalização desta etapa do Projeto Semeadura e do entendimento do papel das mulheres nos territórios onde estavam inseridas, pode-se observar que no andamento da proposta houve um engajamento maior sobre os temas debatidos, demonstrando, na medida em que se discutia aumento do empoderamento e engajamento das mulheres sobre seus direitos, fazendo-se valer a importância e pertinência da continuidade desse projeto de forma ativa, ampliando e tentando alcançar o maior número de participantes.

O apoio da Organização da Sociedade Civil de Interesse Público chamada de Guayí Democracia, Participação e Solidariedade foi fundamental para a realização das ações práticas do 
Projeto Semeadura, Visto que a Guayí possui uma trajetória de engajamento e suporte às ações voltadas às mulheres do campo.

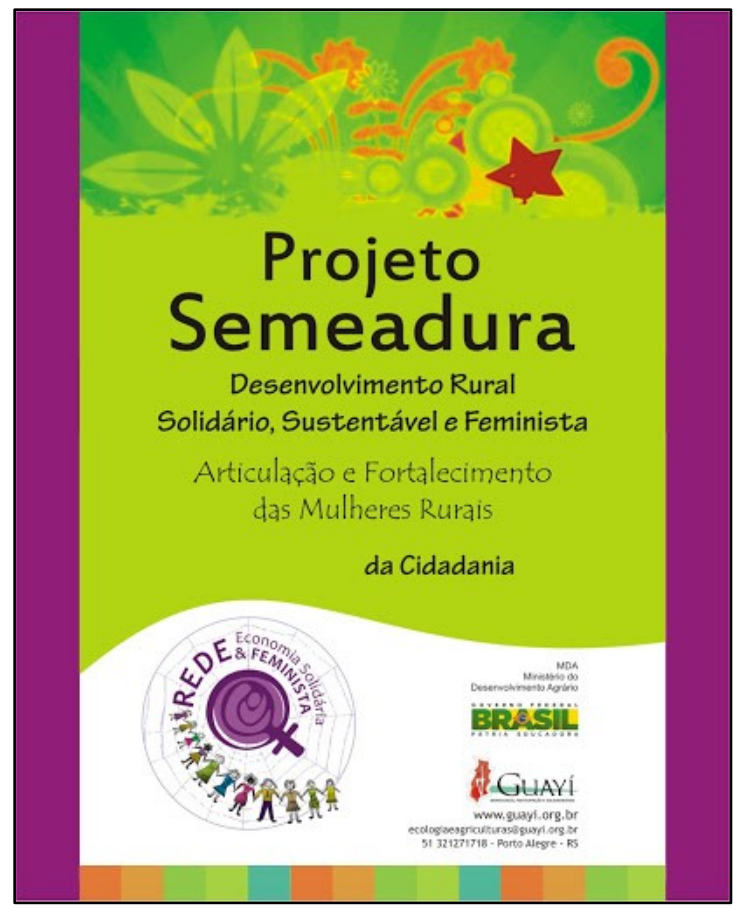

Figura 6 - Cartaz do Projeto Semeadura.

Fonte: Guayí, disponível em: http://guayi.org.br/?page_id=2981, Acesso em: 05.07.2020.

Contextualizar a origem do Projeto Semeadura, é também considerar a história da Guayí, o qual teve seu início de suas atividades no ano de 2001. Foi resultado de diversos processos e contextos políticos e rurais de organização das mulheres do campo, teve seu cerne lançado em 1979, no Grupo de Estudos Agrários que posteriormente deu origem ao movimento sindical da luta pelos direitos da mulher ${ }^{7}$.

\section{CONSIDERAÇÕES FINAIS}

Os territórios rurais são deixados de lado, relegados ao segundo plano. Desse modo, entende-se que não é prioridade, por parte do Estado, criar e implementar políticas públicas para os sujeitos camponeses. È forte a articulação de uma sociedade hegemônica, a qual força a introdução de uma cultura desenvolvimentista capitalista, pressionando muitas vezes os povos do campo a abandonar seu modo de vida e sua cultura, de modo que para muitos destes sujeitos a desterritorialização acaba forçadamente acontecendo; seu espaço de vida é devastado, transformado, com isso a reterritorialização acaba acontecendo em outros territórios, mais precisamente no meio urbano.

\footnotetext{
${ }^{7}$ Informações disponíveis em: http://guayi.org.br/?page_id=1973, acesso em: 05.07.2020.
} 
Do mesmo modo, a Educação construída e voltada a esses sujeitos não é um projeto prioritário, o que "é um equívoco não dar prioridade à educação do campo, como aconteceu durante toda a nossa história" (PROCAMPO, 2013, p.01). Não oferecer condições favoráveis aos povos do campo através de políticas voltadas à permanência com dignidade nesses territórios, torna-se uma forma de agressão à vida destes sujeitos, dos animais e da natureza.

Se, para os homens do campo as políticas são menos presentes, para as mulheres camponesas, viver nesses territórios apresenta sem sombra de dúvidas muitos mais desafios a serem superados. Desse modo, destaca-se que, para as mulheres do campo a principal diferença é marcada justamente pelos papéis sociais que desempenham homens e mulheres no que diz respeito à produção e da reprodução da atividade e do ser doméstico e do público. As mulheres do campo desenvolvem inúmeras jornadas de trabalho e, na maioria das vezes não são respeitadas por isso.

Desse modo, novas estratégias precisam ser problematizadas, a fim de que seja refletido e repensado o cenário em que as mulheres estão inseridas, na tentativa de traçar uma nova realidade para elas nos territórios onde estão, ou onde queiram estar.

É necessário a criação de projetos que utilizem-nas como protagonistas, havendo uma discussão coletiva, com vistas à emancipação e empoderamento feminino, o que se faz cada vez mais necessário no mundo globalizado, culturalizado e interconectado. Percebe-se que a utilização dos meios de articulação social, promove a democratização das/nas relações sociais.

Diante das reflexões feitas, ressalta-se a importância do empoderamento das mulheres através da concepção de que o paradigma de condição de dominação masculina, tem que ser modificado, para dar espaço a uma dinâmica social mais igualitária. Ressalta-se o papel da mulher no meio rural como uma detentora de saberes tradicionais e da propriedade como um todo, pois, o trabalho toma um valor não econômico, mas cultural, em que estabelece a convivência com a natureza a partir de novas relações sociais.

O meio rural é um espaço no qual as relações sociais de desigualdade de gênero são latentes, daí a necessidade de construção da igualdade entre homens e mulheres, sendo através de políticas públicas ou projetos de empoderamento feminino, como no caso do Projeto Semeadura. Esse processo promove a educação a partir da capacitação, da consciência sobre as políticas públicas e seus direitos, destacando-se a importância de que as discussões de relacionamento com a comunidade em que a trabalhadora se insere, não deve fugir do cotidiano diário da luta do campo, condição primeira para que essa população permaneça e viva do campo.

Após a realização das atividades com as participantes do Projeto Semeadura, ficou evidente a importância da organização coletiva das mulheres, como avanço em relação à conquista de direitos e territórios, onde no qual se destaca o processo educativo como de extrema importância, e na luta pela implementação dos direitos, a começar pela reflexão e problematização de quem são, 
e que mundo merecem, estabelecendo espaços de liderança sensíveis à igualdade de gênero, respeitando e apoiando os direitos humanos e o bem-estar de todas as mulheres trabalhadoras.

\section{REFERÊNCIAS}

BRASIL. Ministério do Desenvolvimento Agrário. Políticas Públicas para as Mulheres Rurais no Brasil. Disponível em: http://www.mda.gov.br/sitemda/sites/sitemda/files/ceazine.pdf. Acesso em: 23 nov. 2019.

BRASIL. Ministério do Desenvolvimento Agrário (MDA). Assessoria Especial de Gênero, Raça e Etnia. Programa de documentação da trabalhadora rural. Brasil, DF, 2009.

BRASIL. Ministério do Desenvolvimento Agrário. $2^{\text {a }}$ Conferência Nacional de Desenvolvimento Rural Sustentável e Solidário. Documento Nacional. Brasília-DF, 2013.

BEIRAS, A.; BRONZ, A. Metodologia de grupos reflexivos de gênero. 1. ed. Rio de Janeiro: Instituto Noos, 2016. 162p.

COTAG. Margaridas na luta por: desenvolvimento sustentável com justiça, autonomia e igualdade e liberdade. Disponível em: http://www.contag.org.br/imagens/fcaderno.pdf, Acesso em: 02 fev. 2020.

FISCHER, I. R. Relações de gênero na agricultura familiar no acampamento de Sem Terra no Engenho Prado. In: SCOTT, P.; CORDEIRO, R. (Orgs.). Agricultura familiar e gênero: práticas, movimentos e políticas públicas. Recife: Ed. Universitária da UFPE, 2006. p. 193-204.

GUAYI. Projeto Semeadura. Disponível em: http://guayi.org.br/?page_id=2981\#. Acesso em: 28 jun. 2020.

HOFLInG, E. M. Estado e Políticas (Públicas) sociais. Cadernos Cedes, ano XXI, no 55, novembro/2001.

KÖCHE, J. C. Fundamentos de metodologia científica: teoria da ciência e prática da pesquisa. 15. ed. Petrópolis: Vozes, 1997. 184p.

MDA. Reforma agrária: um compromisso de todos. Brasília: Presidência da República/SECOM, 2002. Disponível em: http://www.planalto.gov.br/publi_04/. Acesso em: 12 jun. 2020.

. Manual Operacional do Programa Nacional de Crédito Fundiário - Linha CPR. 1. ed. Brasília: MDA, 2009. 60p

MMC BRASIL. História do Movimento de Mulheres Camponesas. Disponível em: http://www.mmcbrasil.com.br/site/node/44. Acesso em: 28 jun. 2020.

MMC BRASIL. Lutas do Movimento de Mulheres Camponesas. Disponível em: http://www.mmcbrasil.com.br/site/node/47. Acesso em: 28 jun. 2020.

MMC BRASIL. Feminismo camponês e popular. Cartilha. Associação Nacional de Mulheres Camponesas, Brasil, 2018. Disponível em: http://www.mmcbrasil.com.br/site/materiais/download/ Cartilha.pdf, Acesso em: 28 jun. 2020. 
PROINF. Manual Operacional do PROINF 2012: ação orçamentária de apoio a projetos de Infraestrutura e serviços em Territórios Rurais. Brasília: Ministério do Desenvolvimento Agrário, 2012. 22p.

SILIPRANDI, E.; CINTRÃO, R. Mulheres rurais e políticas públicas no Brasil: abrindo espaços para o seu reconhecimento como cidadãs. In: GRISA, C.; SCHNEIDER, S. (Org.). Políticas públicas de desenvolvimento rural no Brasil. Porto Alegre: Editora da UFRGS, 2015.

SPIVAK, G. C. Pode o Subalterno Falar? 1. ed. Belo Horizonte: Editora UFMG, 2010. 133p.

TEDESCHI, L. A. Mulheres camponesas da região do noroeste do Rio Grande do Sul: identidades e representações sociais (1970 - 1990). 2007. 240 f. Tese (Doutorado em História) Universidade do Vale do Rio dos Sinos, São Leopoldo, 2007. 